\title{
FINANCE
}

\section{To CORP or not to CORP: Strategic tax considerations for investing}

\author{
Daniel A Peters MD MBA FRCSC ${ }^{1}$, Douglas A McKay MD MBA FRCSC ${ }^{2}$
}

$\mathrm{T}$ he introduction of the medical corporation in Canada has opened a host of financial opportunities for physicians. When residents first graduate, they are advised by most of their colleagues to incorporate. The reasons vary. Some advocate that this affords an effective means of income splitting. There are advantages in sequestering professionally derived fees from other sources of income. There may also be some advantages in terms of estate planning.

The most often cited benefit, however, is the tax rate. In 2012, the corporate tax rate on business income dropped to $15 \%$ for most corporations. In contrast, for many plastic surgeons, professionally derived income would be taxed at the highest marginal tax rate of close to $50 \%$. This rate disparity has important implications in terms of the decision to sequester income within the corporation rather than realize it personally.

\section{HOW MUCH SHOULD I PAY MYSELF?}

One question that is often asked is how much money should be withdrawn from the corporation to achieve the most efficient overall tax strategy. There are several factors that influence this decision. The most practical implication is the decision regarding how much money the physician needs to support his or her lifestyle. Other factors include implications for the Canada Pension Plan and the marginal rates payable by the various people with whom income can be split. From a savings perspective, however, many point to an amount that maximizes registered retirement savings plan (RRSP) contributions.

Throughout most of our careers, physicians are advised to maximize our RRSP contributions. It is suggested that the most tax efficient strategy involves maximizing RRSP contributions to capitalize on the tax deferral. We use the words 'tax deferral' because, ultimately, the income derived from the RRSP will be subject to taxation. However, this taxation will likely be incurred many years later and, possibly, when the individual is paying a lower rate.

While tax-deferral techniques offer benefits to those whose personal earned income is high, they require that sufficient earned income be diverted from the corporation to support the earned income qualifications. RRSP contributions are dependent not on the total amount of income accruing to an individual but rather by income that is 'earned'. This income includes funds derived from salaries and professional fees. It also includes net earnings from self-employment. However, this income excludes investment income and income derived from the disposition of trusts, etc. To support the earned income qualifications physicians must, therefore, withdraw funds from the corporation that have been derived from professional fees. This is precisely the income that is being sequestered within the corporation to avoid higher marginal rates. This diverted income is then taxed at the higher marginal rates applicable to personal income.

\section{THE RRSP MAXIMIZATION STRATEGY}

When the goal of tax-deferral maximization is pursued, the objective is to withdraw sufficient income from the corporation to qualify for the maximum RRSP contribution, which is $18 \%$ of earned income up to a maximum of $\$ 22,970$ in 2012 . The accounting for this income will vary depending on the sources of earned income. However, to make the math easy, for most people, this will represent approximately $\$ 140 \mathrm{~K}$ in earned income. This income will be subject to the marginal

tax rates at the personal level and, for most, this will translate into a tax bill of approximately $\$ 40 \mathrm{~K}$, an effective tax rate of about $33 \%$.

The investment can then accrue within the RRSP plan and compound without being subject to current taxation. The tax will only be paid when the investments are realized during retirement. In the event that redemption occurs prematurely, in most cases, significant taxes are incurred. This means that the price of tax deferral is a loss of flexibility with respect to the time at which these funds are available for consumption.

\section{THE CORPORATE STRATEGY}

In this scenario, money is withdrawn from the corporation only as required to support private lifestyle rather than in an amount designed to maximize RRSP contributions. Savings are retained within the corporation. Earned income is taxed at the lower corporate rate, leaving more funds available for savings compared with the after-tax income in the personal taxation scenario. This means that the principal invested can be higher if the funds are retained in the corporation.

It must be emphasized that while income derived from professional fees are taxed at the corporate rate, this is not true of income derived from investments. Investments are taxed at a tax rate equivalent to the top personal marginal tax rate, which in most cases varies between $46 \%$ and $50 \%$. Therefore, while the principal invested may be higher, the income derived from that capital is taxed at a higher marginal rate.

The temporal restrictions imposed by RRSP contributions are mitigated by sequestering the funds within the corporation. Investments can be cashed at any time without penalties. However, restrictions on the use of those funds remain. Because corporate cash cannot be used for personal purposes, there are restrictions on how those funds can be used.

\section{WHAT TO DO?}

Each strategy has strengths and weaknesses. The RRSP maximization strategy confers advantages in terms of allowing investment income to compound tax free. The tax-deferral technique has advantages in terms of reducing the current tax burden. However, it presupposes that at the time of RRSP redemption, the physician will be subject to lower marginal tax rates. This may not be true in all cases. Furthermore, this strategy carries restrictions in terms of the timing at which the funds are available for personal use.

The corporate strategy may increase the principal available for investment but carries the disadvantage of subjecting investment income subject to high marginal rates. In addition, by sequestering funds within the corporation, restrictions are imposed in terms of the purposes for which these funds can be used.

There is no question that everyone will have different personal circumstances. A balance must always be achieved between RRSP room, Canada Pension Plan benefits, tax rates and flexibility. However, the use of corporate investments offers the first real alternative to RRSP maximization and the generally accepted wisdom of RRSP maximization may not apply in all cases. We suggest that you consider your circumstances and discuss with your financial professionals what strategy may best meet your needs.

${ }^{1}$ Divison of Plastic Surgery, Department of Surgery and Telfer School of Management, University of Ottawa, Ottawa; ${ }^{2}$ Divison of Plastic Surgery,

Department of Surgery, Queen's University, Hotel Dieu Hospital, Kingston, Ontario

Correspondence: Dr Daniel A Peters, University of Ottawa, PO Box 2013, 1053 Carling Avenue, Ottawa, Ontario K1Y 4 E9.

Telephone 613-795-5555 ext 13712, fax 613-761-4025, e-mail dannypeters1@gmail.com 